\title{
AVALIAÇÃO DE COMPETITIVIDADE E GERENCIAMENTO DE DESTINOS TURÍSTICOS: UMA APLICAÇÃO NO SUL DO BRASIL
}

\author{
Elenara Viera de Vieira - Centro Universitário Metodista do IPA ${ }^{1}$ \\ Valmir Emil Hoffmann - UNB
}

Resumo: A competitividade tem muitas definições, e para determiná-la no contexto de um destino turístico (atratividade) é preciso considerar dimensões, variáveis e indicadores para que se possa mensurá-la com maior exatidão. Nesse sentido, este estudo teve por objetivo identificar e analisar os recursos de apoio e gerenciamento das cidades de Santana do Livramento e Uruguaiana por meio da aplicação do modelo de Dwyer e Kim (2003), bem como verificar a relação existente entre os elementos de competitividade e o desempenho socioeconômico percebido em cada cidade. O estudo teve caráter exploratório, descritivo e conclusivo, e consistiu em um estudo comparativo realizado em duas etapas: uma exploratória e outra descritiva-conclusiva. Os stakeholders turísticos selecionados para este estudo foram os hotéis, os restaurantes e o comércio, sendo o questionário aplicado a 192 respondentes entre as cidades de Santana do Livramento e Uruguaiana, RS. Os dados foram tratados com instrumental estatístico descritivo e inferencial, utilizandose da análise univariada e multivariada. Os resultados evidenciaram, que apesar das semelhanças, as cidades são competitivas distintivamente, ou seja, uma valoriza aspectos de forma positiva que a outra não percebe dessa forma.

Palavras-chave: Competitividade; Destino turístico; Stakeholders; Modelos de competitividade; Análise fatorial.

\section{COMPETITIVENESS EVALUATION AND MANAGEMENT OF TOURIST DESTINATIONS: AN APPLICATION IN SOUTHERN BRAZIL}

Abstract: Competitiveness has many definitions, and to define it in the context of a tourist destination (attractiveness) it is necessary to consider dimensions, variables and indicators to measure it with greater accuracy. In this sense, this study analyzes the elements of competitiveness of the tourism destinations of Santana do Livramento and Uruguaiana, based on the model of Dwyer and Kim (2001, 2003). The elected model proposed by Dwyer and Kim (2001) consists of seven variables. . This is an exploratory, a descriptive and a conclusive study, which consisted of a comparative study carried out in two stages: one exploratory, and the other descriptive-conclusive. The first part sought to identify who are the most important tourist stakeholders, as the basis for the application of a survey in the conclusive research. The tourism stakeholders selected for this study were hotels, restaurants and commerce (stores), and the questionnaire was applied to 192 people for both towns. The data were analyzed using descriptive and inferential statistical analysis,

\footnotetext{
${ }^{1}$ E. mail: eleviera@hotmail.com

2 E.mail: ehoffmann@unb.br. Endereço: Campus Universitário Darcy Ribeiro - ICC Asa Norte, Bloco B - $1^{\circ}$ Andar, Sala 576 - CEP 70910-900 - Brasília - DF
}

VIEIRA, E. V.; HOFFMANN, V.E. Avaliação De Competitividade E Gerenciamento De Destinos Turísticos: Uma Aplicação No Sul Do Brasil. Revista de Empreendedorismo e 
using univariate and multivariate data analysis (factor analysis of the main components and discriminant analysis). The results demonstrate that despite the similarities between the two towns, they are competitively distinct; one values aspects in a positive way, while the other does not see things from this perspective. Uruguaiana had higher averages and standard deviation for the category resources (inherited and created), while Santana do Livramento obtained more positive results in the categories support resources and management of the destination.

Keywords: Competitiveness Tourist destination; Stakeholders; Models of competitiveness; Factor analysis.

\section{Introdução}

É de verificar-se que a atividade turística tornou-se um "negócio" pelo mundo todo. Seu êxito não depende apenas da ação de uma empresa, mas também do destino turístico onde a empresa está localizada também pelo fato de que tanto no Brasil como em outros países, o turismo é uma atividade econômica que se alicerça em pequenas e médias empresas (IBGE, 2007; SEBRAE, 2008). Por seu tamanho, seu poder de mercado é menor e a condição de mudar a realidade que as cerca, principalmente se falando de turismo, depende mais da cooperação, como apontaram Mottiar e Tucker (2007).

Considerando que o sucesso na competição está vinculado à criação e sustentação de vantagens competitivas que cada concorrente deve buscar para responder melhor aos hiatos deixados pela atuação de seus concorrentes (COYNE, 1986), no turismo, a percepção sobre esse tipo de vantagem não é mais medida somente pelas belezas naturais de um destino, mas sim pela interação e cooperação entre as organizações turísticas (SELIN; BEASON, 1991), pelo preço do produto turístico (CROUCH, 1992, DWYER et al., 2001) como também pela qualidade de vida local (NEWALL, 1992, DINIZ FILHO; VICENTINI, 2004). Esses seriam os hiatos a serem atendidos.

De acordo com Dwyer e Kim (2003), para obter uma vantagem competitiva, um destino deve assegurar que toda a sua atratividade, bem como a qualidade de experiência que proporciona ao visitante, sejam superiores àquelas nas quais exista este mesmo potencial. Essa definição reforça aquela indicada por Coyne (1986), quando o autor sustenta que, para se obter uma vantagem competitiva sustentável o

VIEIRA, E. V.; HOFFMANN, V.E. Avaliação De Competitividade E Gerenciamento De Destinos Turísticos: Uma Aplicação No Sul Do Brasil. Revista de Empreendedorismo e 
ator deve lograr que seu produto/serviço seja preferido ao longo do tempo pelo consumidor em detrimento daqueles que são oferecidos pelos concorrentes.

Diferentes modelos de avaliação de competitividade em destinos turísticos têm evidenciado a descrição de elementos que explicam a eficácia do destino em termos de ganho de parte do mercado, desconsiderando o fator de interrelacionamento entre eles, para que possam influir na sua sustentabilidade (JONKER; HEAT; DU TOIT, 2004). Nesse sentido, Dwyer e $\operatorname{Kim}(2001,2003)$ popõem um modelo para ser aplicado em destinos turísticos baseado naquele criado preliminarmente por Ritchie e Crouch (2000). Porém, com um formato integrado, diferentemente de outros, voltados à indústria manufatureira (PORTER, 1993; ESSER et al., 1994) ou voltados para destinos específicos (HEATH, 2003; JONKER, 2004), ou com características em particular (KOZAK; RIMMINGTON, 1999, YOON, 2002).

O uso do modelo de Dwyer e Kim (2003) para avaliação de competitividade de destinos turísticos está alicerçado nas limitações e sugestões existentes em alguns dos modelos de avaliação desse tipo de competitividade já estudados (BORDAS, 1994; CROUCH; RITCHIE, 1999, KOZAK; RIMMINGTON, 1999, BUHALIS, 2000, HEATH, 2003, JONKER, 2004). Tais autores fizeram tentativas para a elaboração de um modelo único que pudesse ser aplicado de forma ampla às destinações turísticas. Entretanto, cada um deles baseava-se em um número determinado de elementos que nem sempre eram interligados, no sentido de identificação, resultando em uma aplicabilidade não consensual por parte de diferentes pesquisadores.

No estudo de Milman e Pizam (1995), foram considerados como elementos de investigação, os visitantes e turistas. Contudo, esses atores têm contato apenas durante o período de sua estada, além de conhecimento limitado sobre o destino. Além disso, a constituição multifacetada dos elementos que compõem o sistema turístico de um destino, tanto estáticos (recursos naturais e criados) quanto dinâmicos (stakeholders), e também o próprio bem estar local (como resultado da qualidade de vida alcançada para essa população), demandam pesquisas empíricas que proporcionem uma visão acerca dos elementos de competitividade de um 
destino, que não os usuais visitantes e turistas (HEATH, 2003, JONKER, 2004). Dessa maneira, entende-se que as empresas pequenas e médias empresas locais podem devem ser o foco de um trabalho que discuta competitividade.

Assim, este artigo tem por objetivo analisar os elementos de gerenciamento das cidades de Santana do Livramento e Uruguaiana, por meio da aplicação do modelo de Dwyer e Kim (2001, 2003), bem como verificar a relação existente entre os elementos de competitividade e o desempenho socioeconômico percebido em cada cidade. Este trabalho está dividido em cinco partes. A primeira constitui a presente introdução; a segunda apresenta o referencial teórico utilizado; a terceira é explanada a metodologia aplicada; os resultados aparecem na quarta parte; e por fim, as conclusões. As referências consultadas seguem como parte final do artigo.

\section{Referencial Teórico}

Nos últimos anos, a literatura internacional especializada na área do turismo elucidou o conceito de destino turístico, focando a atenção nas ações estratégicas para a comercialização de um lugar, considerando-o como um sistema de atores, entre eles as pequenas e médias empresas que predominam no setor, que coopera para a promoção de um produto turístico integrado (CAPONE, 2004). Dessa forma, a competitividade em destinos turísticos como objeto de análise deve evidenciar, primeiramente, os dois componentes essenciais do sistema turístico: a origem e o destino. A origem é dada pela visitação dos potenciais e atuais turistas no destino e tem relação com sua localidade de procedência, sendo também chamada no turismo por demanda turística (COOPER et al., 2002). O destino, de um modo mais amplo, é uma unidade essencial dentro da dimensão onde o turismo encontra-se alicerçado.

O uso de indicadores para a mensuração da competitividade em destinos turísticos tem sido uma prática comum, pois permitem a obtenção de uma informação mais sólida, servindo como auxílio na correção de práticas para a melhoria de sua gestão sustentável (PÉREZ; MESANAT, 2006). De acordo com Dwyer e Kim (2001), para que se possam desenvolver indicadores para a mensuração da competitividade de uma nação ou destino, é preciso que, de alguma

VIEIRA, E. V.; HOFFMANN, V.E. Avaliação De Competitividade E Gerenciamento De Destinos Turísticos: Uma Aplicação No Sul Do Brasil. Revista de Empreendedorismo e 
forma, os itens e variáveis que serão utilizados considerem o reconhecimento da importância da percepção de competitividade por parte do consumidor, ou seja, o visitante ou o turista. É preciso pensar que no contexto do turismo nem todas as influências na competitividade são objetivamente quantificáveis e passíveis de uma mensuração, envolvendo uma distinção entre a realidade da situação e a percepção por parte do visitante ou turista (DWYER; KIM, 2001), pois o produto turístico reside na experiência sensorial, sendo quase sempre intangível.

Alguns modelos gerais como os de Porter (1993) e Esser et al. (1994), não foram desenvolvidos especificamente para a avaliação de competitividade de destinos turísticos, tendo seu foco direcionado à avaliação de produtos mais convencionais voltados à área da manufatura, ainda que Porter (1993) tenha executado alguns estudos sobre o turismo na Europa utilizando seu modelo. Além disso, não há nos ambos modelos uma preocupação específica sobre o setor turístico nem sobre o tamanho típico dos negócios no setor.

Seguindo esses modelos, outros pesquisadores criaram instrumentos de avaliação de competitividade unicamente para destinos turísticos. Neles, parece evidente o empenho em captar, de forma mais completa, as relações entre os fatores e, nesse esforço, considerar os demais elementos como parte do produto, diferenciando-os dos âmbitos micro e macro do entorno competitivo que também serão inclusos. Assim, destacam-se os modelos específicos de Ritchie e Crouch (2000); o de Heath (2003); e o de Dwyer; Kim (2003). Por limitação de espaço, foco recairá apenas sobre o modelo específico aplicado neste estudo. 
Figura 1: Modelo de avaliação de competitividade em destinações

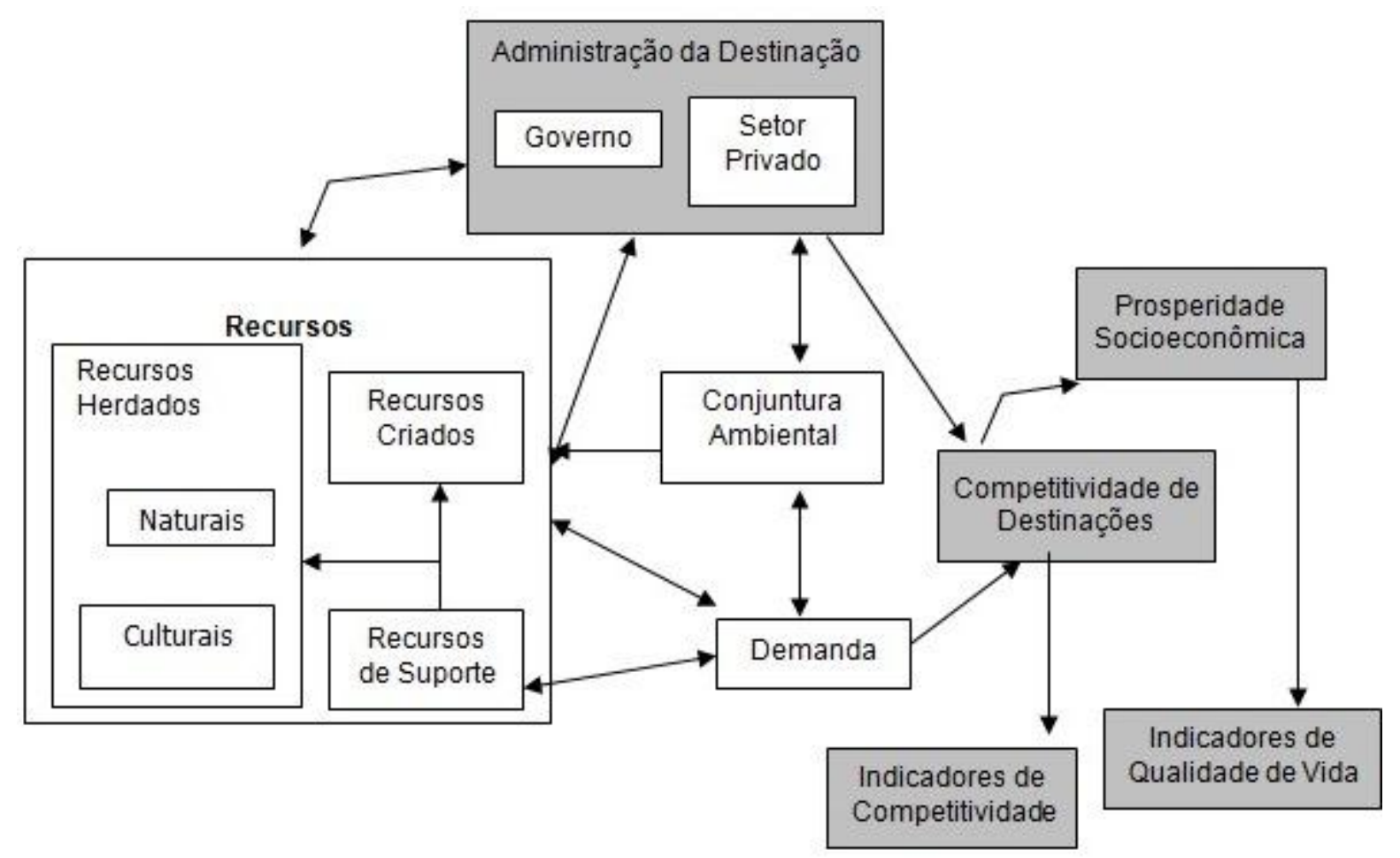

Fonte: Baseado em Dwyer e Kim, 2003, p. 378.

O modelo proposto por Dwyer e Kim (2003) contempla elementos integrados e mesmo complementares de outras propostas. Os determinantes de competitividade de um destino nesse modelo apresentam-se dispostos em quadrantes-chave. O modelo explora a Visão Baseada em Recursos (VBR), descrita inicialmente por Barney (1991), ao indicar que competitividade deve ser avaliada a partir dos recursos. Como Barney (1991) já havia indicado que os recursos seriam uma maneira complementar ao modelo de Porter (1986), ao procurar entender a competitividade, por consequência, infere-se que também o modelo de Dwyer e Kim (2003) suplementa aquele apresentado por Porter (1986). Contudo, os autores entendem que tanto a administração da destinação, a conjuntura ambiental e as condições da demanda, têm relevo nessa análise. Todos esses elementos impactam na competitividade das destinações, avaliada por indicadores de competitividade, que traz a prosperidade socioeconômica local (ou regional), medida por indicadores 
de qualidade de vida local (ou regional). A Figura 1 apresenta o modelo, com destaque para as três partes consideradas no recorte feito neste artigo: a percepção sobre os recursos e as afirmações acerca dos indicadores de competitividade da destinação.

\section{O Quadrante do Gerenciamento da Destinação}

Segundo o modelo de Dwyer e Kim $(2001,2003)$, são cinco as forças que regem a administração de um destino: a gestão do marketing, a gestão de planejamento e desenvolvimento, a gestão organizacional municipal, o desenvolvimento dos recursos humanos e a gestão ambiental.

A promoção de um destino implica no desenvolvimento de canais de comunicação com os clientes e com os stakeholders, para o aumento da persuasão na compra pelo produto (BUHALIS, 2000). Uma das funções essenciais dos gestores de marketing de um destino é a criação de sua imagem, pois ela será o somatório das ideias e crenças que as pessoas têm sobre um determinado lugar (KOTLER et al., 2005). De acordo com Uysal, Chen e Williams (2000), a relevância do posicionamento da imagem e da marca como determinantes competitivos de ganho de parcela no mercado, está associada à complexa ação e coordenação de esforços entre todos os interessados no ganho da localidade e deve contemplar a percepção sob diferentes focos segmentais no mercado, tais como: demográfico, psicográfico e comportamental (DWYER; KIM, 2003).

De modo particular, como as empresas turísticas são pequenos e médios negócios, sua capacidade de investimento em marketing para sua promoção é difícil e para a promoção do destino quase impossível em função do investimento necessário. Uma solução possível é o estabelecimento de parcerias ou redes entre os setores público e privado, e uma cooperação mais próxima entre todos os fornecedores de serviços turísticos locais (MOTTIAR; TUCKER, 2007; BERITELLI, 2011; COSTA; COSTA; MIRANDA JÚNIOR, 2012; HOFFMANN; CAMPOS, 2013).

O planejamento e desenvolvimento dos destinos envolvem várias partes e distintas perspectivas entre os interessados no processo e que estão presentes nos VIEIRA, E. V.; HOFFMANN, V.E. Avaliação De Competitividade E Gerenciamento De Destinos Turísticos: Uma Aplicação No Sul Do Brasil. Revista de Empreendedorismo e 
destinos. Essa diversidade se reflete também em como cada ator acredita impactar na gestão da destinação e isso por vezes é divergente, como apontaram Costa e Hoffmann (2006). Devido a essa diversidade, é preciso a utilização de um modelo competitivo que verifique as relações entre os diferentes stakeholders envolvidos (HASSAN, 2000). Relacionamentos que proporcionem benefícios mútuos aos diferentes stakeholders contribuem para um desenvolvimento de um ambiente próativo e estratégias sociais que permitem a melhoria da localidade e marca do produto turístico (YOON, 2002).

$\mathrm{Na}$ atividade turística em especial, um relacionamento construído entre setor privado, público, organizações não governamentais e/ou grupos da comunidade local, permite maior aproximação em direção à sustentabilidade (HASSAN, 2000) além de se conseguir objetivos de longo prazo como reporta Bonet (2004).

No que tange às questões para o desenvolvimento dos recursos humanos, sua função parece ser essencial em qualquer âmbito, tanto nas organizações quanto nos destinos. $\mathrm{Na}$ importância atribuída ao turismo sustentável, as questões relevantes remetem à participação de forças vivas no planejamento e na gestão dos destinos. Há ainda a preocupação com os recursos herdados, as questões econômicas, os condicionantes dos transportes, as novas modalidades de trabalho em benefício dos residentes e outras situações que permitam melhorar seu bem estar. Além disso, parecem importantes aquelas que promovam a participação e a integração das populações locais, individualmente ou em grupos, de forma que o turismo estabeleça um processo de interesse comunitário (BAPTISTA, 2003).

Assim, uma maneira de ressaltar as potencialidades do destino está na identificação e no investimento para a formação de agentes locais voltados à atividade turística, onde a redefinição dos papéis e as prioridades do estado e da iniciativa privada estejam direcionadas ao processo eficaz de crescimento e melhoria da capacitação profissional (UDENAL; CAMPOS; FAXINA., 2004). Os stakeholders turísticos devem entender que as práticas de gestão dos recursos humanos e programas que auxiliem na educação e na capacitação das pessoas, fortalecem o conhecimento organizacional e promovem a vantagem competitiva sustentável (DWYER; KIM, 2003).

VIEIRA, E. V.; HOFFMANN, V.E. Avaliação De Competitividade E Gerenciamento De Destinos Turísticos: Uma Aplicação No Sul Do Brasil. Revista de Empreendedorismo e 
Quanto à última força mencionada nesse quadrante da gestão do destino, a ambiental em um sentido mais restrito, deve-se mencionar que a terminologia ambiente refere-se ao ambiente físico, tanto o natural quanto o criado. Porém, em uma conotação mais ampla, pode-se dizer que a palavra ambiente deve considerar elementos sociais e culturais. A gestão sustentável de um destino turístico visualiza a localidade mais do que o somatório das partes interessadas, procurando buscar alternativas que a viabilizem em longo prazo para turistas e residentes (JAMIESON, 2001).

Parece cabível ponderar que a dependência da continuidade da atividade turística em um destino está na proteção ao meio ambiente e na cultura específica local, além dos atributos garantidos pelas estratégias de planejamento do turismo oriundos das ações integradas (FONSECA; FONSECA, 2004). No caso particular das empresas turísticas, por serem pequenos negócios é de se esperar que seus proprietários tenham maior vinculação com o destino e dessa forma se sintam mais pertinentes a ele, o que pode se traduzir em proteção tanto de recursos naturais como da cultura local. Um estudo conduzido pela Associação dos Hotéis e Pousadas de Maragogi e Japaratinga - AHMAJA citado por Costa, Costa e Miranda Júnior (2012) mostrou que naquela região alagoana cerca de $70 \%$ da hospedagem era oferecida por negócios pequenos e familiares, mais do que isso, o estudo evidenciou que quase a totalidade das empresas não estava envolvida em projetos ou ações relacionadas aos recursos naturais.

\section{O Quadrante da Competitividade do Destino}

A análise dos fatores que determinam a competitividade de um destino (variáveis e indicadores), acompanhada dos múltiplos interesses que compõem o seu entorno, parece fazer de sua investigação uma questão dificultosa, porém necessária, agregando-se alguns pontos. Percebe-se que um primeiro ponto advém deste conceito relativo, cuja medida pode variar em função do período de tempo que se adote como referência para a investigação. Ademais, existem não só indicadores que podem ser medidos de forma quantitativa, mas alguns subjetivos, que permitem

VIEIRA, E. V.; HOFFMANN, V.E. Avaliação De Competitividade E Gerenciamento De Destinos Turísticos: Uma Aplicação No Sul Do Brasil. Revista de Empreendedorismo e 
ser mensurados por meio das impressões de cada visitante, tornando-os estudos qualitativos. Mesmo assim, ainda existem alguns elementos que podem ser tanto objetivos quanto subjetivos em sua avaliação (DWYER; KIM, 2001, 2003).

Um segundo ponto diz respeito ao grau de risco inerente ao êxito, em um sentido mais global, quando se evidencia a competitividade total de uma nação. $O$ modelo desenvolvido por Dwyer e $\operatorname{Kim}(2001,2003)$ sugere uma miríade de indicadores de competitividade para avaliação de um destino turístico, e eles aparecem relacionados em função do quadrante. Em geral, mensurar o turismo por meio de coleta, análise e interpretação de estatísticas, é essencial para a avaliação de seu impacto e grau de competitividade turística nas diferentes escalas geográficas. Porém, de acordo com Page (2005), as estatísticas relacionadas à atividade turística geralmente são estimadas e não revelam um padrão de comportamento efetivo.

\section{O Quadrante da Prosperidade Socioeconômica e seus Indicadores de Desempenho}

Estudiosos como Ritchie e Crouch (2000) enfatizaram a necessidade das pesquisas sobre competitividade em destinos turísticos se voltarem a medições quantitativas em relação aos vários fatores determinantes do sucesso. Contudo, existem poucos estudos referentes ao desempenho específico do turismo. A maioria examina a área hoteleira sem considerar sua interdependência com as demais atividades turísticas (YILMAZ; BITICI, 2006), ainda que algumas iniciativas sobre cooperação possam percebidas (MAZARO; VARZIN, 2008). Dessa forma, a compreensão acerca dos fatores que afetam o crescimento do turismo é condição primordial para seu planejamento, operação e pesquisa (CHO, 2001).

No que diz respeito à medição, Neely, Gregory e Platts (1995) sugerem que o valor de desempenho que uma determinada organização, ou atividade específica atinge é em função de suas ações eficientes e eficazes. Para esses autores, seu sistema de medição está no conjunto de parâmetros métricos usados para quantificar essas ações. Phillips (1999) complementa registrando que, para efeito de

VIEIRA, E. V.; HOFFMANN, V.E. Avaliação De Competitividade E Gerenciamento De Destinos Turísticos: Uma Aplicação No Sul Do Brasil. Revista de Empreendedorismo e 
comparações, os pesquisadores devem tentar selecionar conceitos e indicadores que sejam correlatos com a área ou organizações que se deseja estudar.

\section{Metodologia}

Este trabalho empírico possui caráter exploratório, descritivo e conclusivo, baseando-se em um estudo comparativo para análise dos elementos de competitividade por meio de um modelo aplicado a dois destinos turísticos como objeto de análise: Santana do Livramento e Uruguaiana - RS. A discussão teórica levou à escolha do modelo de Dwyer e Kim (2001, 2003). A opção por esses destinos se deu por suas semelhanças geográficas e históricas.

Um dos elementos utilizados por Dwyer e Kim (2001) na aplicação do modelo foi a eleição dos stakeholders turísticos para a obtenção de respostas, excluíndo-se dentre eles os visitantes. Por essa razão, elencaram-se como o universo da pesquisa, os stakeholders turísticos (diretores, gerentes e/ou proprietários, chefes e subchefes) das pequenas e médias empresas turísticas privadas identificadas na fase exploratória. Como o turismo local é eminentemente de compras, optou-se por lojas que trabalham com a venda de vestuário e artigos de souvenir, tendo como razão principal, a área de localização central e ainda por serem as mais procuradas pelos turistas, segundo informações oriundas das entrevistas com os stakeholders de ambas as cidades. O método de amostragem que foi utilizado é o probabilístico estratificado, utilizando-se parâmetros de $5 \%$ de erro amostral e $95 \%$ de confiabilidade (BARBETTA, 2001), chegando-se a uma amostra de 192 respondentes entre as duas cidades, composta de pequenas e médias empresas.

A coleta dos dados teve duas etapas. A primeira, cujo caráter foi exploratório, teve a intenção de buscar junto aos stakeholders turísticos de cada cidade, por meio de entrevista estruturada, quais deles eram mais relevantes para cada destino e, assim, poder aplicar o questionário somente com os grupos indicados, de modo a fazer um recorte mais preciso. Nessa etapa, foram determinados os seguintes stakeholders: empreendimentos hoteleiros, exceto pousadas e motéis que não foram citados, restaurantes e bares delimitados pela localização em áreas centrais e 
turísticas da cidade, e o comércio em geral onde a atividade principal fosse a venda de vestuário e artigos de souvernir, como também um stakeholder do setor público: a Prefeitura Municipal. A segunda etapa envolveu a pesquisa quantitativa do tipo survey através do estudo de campo, que ocorreu por meio de um questionário estruturado e direcionado ao levantamento dos elementos de competitividade identificados no modelo de Dwyer e Kim $(2001,2003)$, com uma escala contínua de 7 pontos, sendo 1 para o mais baixo grau e 7 para o mais alto.

O modelo proposto por Dwyer e Kim (2001) contempla elementos integrados e os determinantes de competitividade de um destino, que se apresentam dispostos sob quadrantes-chave neste modelo.

No que diz respeito aos elementos de gerenciamento da destinação, os indicadores foram divididos em duas partes. A primeira referiu-se às variáveis pertinentes ao planejamento, ao desenvolvimento e às pesquisas da destinação. A segunda, a aspectos relacionados à comunidade e aos visitantes sobre educação $e$ treinamento.

Os dados coletados nos questionários foram analisados através da estatística descritiva e inferencial, uni e multivariada. A análise descritiva foi feita com base na média e desvio padrão para as variáveis quantitativas.

Dentre as técnicas multivariadas elegeu-se, primeiramente, a análise fatorial de componentes principais e análise dos fatores comuns. Além da análise discriminante, executada posteriormente, aplicou-se a intragrupos para determinar o grau de diferença que há entre as duas cidades, o que gerou a classificação matriz. $\mathrm{Na}$ extração dos fatores pelo método de análise dos componentes principais, realizou-se a rotação varimax. Como a carga fatorial representa a correlação entre a variável original e o fator, optou-se pelo corte igual ou superior a 0,6 recomendado por Hair et al (2005).Para a extração do número de fatores, adotou-se o critério de Kaiser, que propõe considerar apenas os autovalores superiores a 1, demonstrando que esses seriam os valores estatisticamente significativos.

Dando seguimento ao processo, foi realizada uma análise discriminante para a conclusão de quais fatores apresentavam um $p$ significativo (variáveis/indicadores que mais contribuem para a discrepância).

VIEIRA, E. V.; HOFFMANN, V.E. Avaliação De Competitividade E Gerenciamento De Destinos Turísticos: Uma Aplicação No Sul Do Brasil. Revista de Empreendedorismo e 
A avaliação da competitividade se deu através de indicadores qualitativos, considerando que a percepção nesses casos é a única fonte de informação. A maioria dos órgãos públicos no Brasil não possuem informações precisas e detalhadas sobre turismo, e muitas delas são oriundas apenas de estimativas. A percepção dos stakeholders nesse caso passa a ser uma fonte de informação, se não precisa, mais ou menos próxima da realidade. Esse procedimento já havia sido utilizado anteriormente por Costa (2005) e também por Costa, Costa e Miranda Júnior (2012).

\section{Resultados}

Os indicadores da primeira parte do grupo do gerenciamento do destino direcionados a avaliar as questões específicas de planejamento (Tabela 1) apresentaram médias, em sua maioria, nas duas cidades, posicionadas abaixo do ponto central da escala, isto é, valor 4. Da mesma forma, os desvios-padrão apareceram com baixa variância na comparação das duas cidades. 
Tabela 1- Estatística descritiva do gerenciamento da destinação - parte 1

\begin{tabular}{|c|c|c|c|c|c|}
\hline & \multirow[t]{2}{*}{ Indicador } & \multicolumn{2}{|c|}{$\begin{array}{c}\text { S. do } \\
\text { Livramento }\end{array}$} & \multicolumn{2}{|c|}{ Uruguaiana } \\
\hline & & $\begin{array}{l}\text { Médi } \\
\text { a }\end{array}$ & $\begin{array}{c}\text { Desv. } \\
\text { Padrão }\end{array}$ & $\begin{array}{c}\text { Médi } \\
\text { a }\end{array}$ & $\begin{array}{l}\text { Desv. } \\
\text { Padrão }\end{array}$ \\
\hline Q43 & $\begin{array}{l}\text { Existência de programas que o turismo desenvolva } \\
\text { e/ou proporcione aos residentes (comunidade) }\end{array}$ & 3,58 & 1,853 & 3,11 & 1,657 \\
\hline Q44 & $\begin{array}{l}\text { Qualidade das pesquisas feitas sobre o turismo na } \\
\text { cidade para propor normas e elaborar planos }\end{array}$ & 2,65 & 1,725 & 2,12 & 1,513 \\
\hline Q45 & $\begin{array}{l}\text { A cidade possui uma política clara para um turismo } \\
\text { mais social (ex.: deficientes físicos, idosos, etc.)? }\end{array}$ & 2,30 & 1,495 & 2,36 & 1,541 \\
\hline Q46 & Investimentos para o desenvolvimento do turismo & 3,67 & 1,671 & 4,25 & 1,794 \\
\hline Q47 & $\begin{array}{l}\text { Compromisso do governo local no desenvolvimento } \\
\text { do turismo }\end{array}$ & 3,59 & 1,723 & 4,33 & 1,518 \\
\hline Q48 & $\begin{array}{l}\text { Desenvolvimento do turismo e o crescimento da } \\
\text { indústria turística (lojas, hotéis, restaurantes, etc.) } \\
\text { como um todo }\end{array}$ & 3,79 & 1,594 & 5,08 & 1,568 \\
\hline Q49 & $\begin{array}{l}\text { Reconhecimento por parte do setor público (governo, } \\
\text { instituições) da importância do desenvolvimento de } \\
\text { um turismo sustentável }\end{array}$ & 3,14 & 1,919 & 4,73 & 1,582 \\
\hline Q50 & $\begin{array}{l}\text { Reconhecimento por parte do setor privado da } \\
\text { importância do desenvolvimento de um turismo } \\
\text { sustentável }\end{array}$ & 3,61 & 1,697 & 4,95 & 1,579 \\
\hline Q51 & Apoio dos residentes no desenvolvimento do turismo & 4,05 & 1,235 & 4,52 & 1,314 \\
\hline Q52 & $\begin{array}{l}\text { Nível de cooperação (ex.: alianças estratégicas) entre } \\
\text { as empresas dentro da destinação }\end{array}$ & 4,93 & 1,397 & 4,81 & 1,600 \\
\hline
\end{tabular}

Fonte: Os autores (2013).

Comparando os resultados obtidos nas duas cidades, as médias mais altas em Santana do Livramento referiram-se a indicadores originados de variáveis sobre gestão ambiental e recursos humanos. Uruguaiana, por sua vez, também reconhece um desses indicadores dentro dos mais positivos (importância de um turismo sustentável), e a questão do nível de cooperação entre as empresas dentro do destino. No sentido de formação de alianças estratégicas, também se obteve uma percepção positiva de Uruguaiana.

De todo modo, ambas as cidades reforçaram novamente a questão da existência da cooperação já detectada em outros quadrantes. Em contrapartida, as médias mais baixas nesse quadrante foram percebidas nos mesmos indicadores nas duas cidades e refletem pontos sobre o planejamento municipal. Os indicadores responsáveis foram: a qualidade das pesquisas feitas sobre o turismo e a política clara para um turismo mais social.

VIEIRA, E. V.; HOFFMANN, V.E. Avaliação De Competitividade E Gerenciamento De Destinos Turísticos: Uma Aplicação No Sul Do Brasil. Revista de Empreendedorismo e 
Assim, perceberam-se semelhanças nas duas cidades, o que parece evidenciar que as questões que envolvem o planejamento do turismo, bem como suas pesquisas, carecem de maior atenção por parte do governo municipal, inclusive o apoio dos residentes no desenvolvimento do turismo local. Tais pontos são elucidados na literatura como relevantes para atingir o desenvolvimento aspirado no turismo e os benefícios advindos deste para todos os stakeholders envolvidos no processo (CROUCH; RITCHIE, 1999, DWYER; KIM, 2003, HENRIQUES; LIMA, 2004, ZERMIANI; CRUZ; WÖHLKE, 2004).

Vale dizer que a cooperação no âmbito de destino se notabiliza como fator que permite a continuidade no cenário da competição (BUHALIS, 2000, HEATH, 2003), e que também reduz os custos tidos como coletivos como aqueles relativos ao marketing do destino (BONET, 2004), o que foi realmente percebido nas duas cidades, e que, talvez, seja o ponto de equilíbrio que compense as percepções não tão positivas em relação à administração municipal. De certa maneira, o fato de não existir claramente a cooperação entre atores pode ter repercussões negativas para as empresas, pois como apontam Costa, Costa e Miranda Júnior (2012) em seu estudo, a cooperação traz impactos positivos para as organizações em termos de desempenho.

Contudo, ressalta-se novamente a importância da cooperação entre todos os stakeholders envolvidos para que a competitividade do destino seja sustentável ao longo do tempo, o que parece não ocorrer nos dois destinos quando há hiatos entre o público e o privado. Denota-se uma possível percepção correta da gestão das empresas turísticas privadas, principalmente em Uruguaiana, e a ausência de pontos fundamentais para o crescimento (ou aprimoramento) e/ou desenvolvimento de novos produtos turísticos já que a pesquisa e o planejamento turístico foram apontados como carentes em relação à administração pública desses municípios. $\mathrm{Na}$ mão contrária, justamente o planejamento turístico que envolveu empresas de todos os tamanhos, governo e terceiro setor, foi o que fez de Barcelona um destino turístico consolidado, como indica Bonet (2004).

$\mathrm{Na}$ avaliação mais detalhada sobre os indicadores desse grupo, através da análise fatorial de componentes principais para a extração do número de fatores, 
dos 10 indicadores desse grupo (primeira parte), foram relacionados 3 fatores (Tabela 2).

Tabela 2 - Componentes principais do gerenciamento da destinação - parte 1

\begin{tabular}{l|c|c|c|c}
\hline \multicolumn{2}{c|}{ Extração: componentes principais - Grupo 4 - gerenciamento da destinação - parte 1 } \\
\hline & $\begin{array}{c}\text { Valor da } \\
\text { variável/indicador }\end{array}$ & $\begin{array}{c}\text { \% total da } \\
\text { variância }\end{array}$ & $\begin{array}{c}\text { Cumulativo da } \\
\text { variável/indicador }\end{array}$ & $\begin{array}{c}\text { Cumulativo \% } \\
\text { da variância }\end{array}$ \\
\hline Fator 1 & 3,560487 & 35,60487 & 3,560487 & 35,60487 \\
\hline Fator 2 & 2,297313 & 22,97313 & 5,857800 & 58,57800 \\
\hline Fator 3 & 1,158665 & 11,58665 & 7,016465 & 70,16465 \\
\hline
\end{tabular}

Fonte: Os Autores (2013)

$\mathrm{Na}$ relação de cada indicador com os 3 fatores encontrados, e ao realizar um contraste por meio da análise discriminante (Tabela 3), observou-se que apenas o Fator 3 não apresentou-se como significativo. Porém, para um resultado mais preciso na identificação dos indicadores que discriminam os dois grupos, analisou-se cada um separadamente (valor de $p$ ), chegando-se a apenas um significativo, o Q49 (reconhecimento por parte do setor público da importância de um turismo sustentável), justamente relacionado com o Fator 1, que apresentou maior variância. Os demais apresentaram um $p>0,05$.

Tabela 3 - Sumário da análise da função discriminante do gerenciamento da destinação - parte 1

\begin{tabular}{lccc}
\hline & Wilks' Lambda & F-remove & $p$-level \\
\hline FATOR 1 & 0,971345 & 43,40379 & 0,000000 \\
FATOR 2 & 0,817657 & 6,79064 & 0,009898 \\
FATOR 3 & 0,789303 & 0,03590 & 0,849920 \\
\hline
\end{tabular}

Fonte: Os Autores (2013)

Convém ressaltar a diferença entre as duas cidades, precisamente nas questões que envolvem o governo municipal. Nos aspectos inerentes à percepção sobre turismo sustentável, ressalva-se que o instrumento de pesquisa indicou sua definição, enfatizando não só a questão ambiental. Contudo, não foi possível mensurar quais aspectos em particular da sustentabilidade pesaram mais para se justificar a diferença das médias.

VIEIRA, E. V.; HOFFMANN, V.E. Avaliação De Competitividade E Gerenciamento De Destinos Turísticos: Uma Aplicação No Sul Do Brasil. Revista de Empreendedorismo e 
Passando-se para a apreciação dos indicadores da segunda parte do grupo, comunidade e visitantes - educação e treinamento, encontrou-se médias superiores nas duas cidades em relação à primeira parte do grupo 4, bem como desvios-padrão inferiores (Tabela 4).

Tabela 4 - Estatística descritiva do gerenciamento da destinação - parte 2

\begin{tabular}{|c|c|c|c|c|c|}
\hline & \multirow[t]{2}{*}{ Indicador } & \multicolumn{2}{|c|}{$\begin{array}{c}\text { S. do } \\
\text { Livramento }\end{array}$} & \multicolumn{2}{|c|}{ Uruguaiana } \\
\hline & & $\begin{array}{l}\text { Médi } \\
\text { a }\end{array}$ & $\begin{array}{l}\text { Desv. } \\
\text { Padrão }\end{array}$ & $\begin{array}{l}\text { Médi } \\
\text { a }\end{array}$ & $\begin{array}{l}\text { Desv. } \\
\text { Padrão }\end{array}$ \\
\hline Q53 & $\begin{array}{l}\text { Responsabilidade das empresas turísticas com as } \\
\text { necessidades dos visitantes }\end{array}$ & 5,57 & 0,941 & 5,30 & 1,418 \\
\hline Q54 & $\begin{array}{l}\text { Responsabilidade do desenvolvimento da atividade } \\
\text { turística com as necessidades da comunidade }\end{array}$ & 5,34 & 0,917 & 4,76 & 1,422 \\
\hline Q55 & $\begin{array}{l}\text { Responsabilidade do desenvolvimento da atividade } \\
\text { turística com as necessidades dos visitantes }\end{array}$ & 5,16 & 1,051 & 4,71 & 1,209 \\
\hline Q56 & $\begin{array}{l}\text { Abrangência e qualidade dos programas de } \\
\text { treinamento para a área turística }\end{array}$ & 4,87 & 1,179 & 5,10 & 1,389 \\
\hline Q57 & Perfil dos empregados na área turística (qualificação) & 3,68 & 2,287 & 5,28 & 1,676 \\
\hline Q58 & A visão da cidade reflete os valores dos residentes? & 4,20 & 1,619 & 4,42 & 1,701 \\
\hline Q59 & $\begin{array}{l}\text { Comprometimento do setor público com a educação e } \\
\text { treinamento para o turismo }\end{array}$ & 4,29 & 1,634 & 5,06 & 1,455 \\
\hline Q60 & $\begin{array}{l}\text { Comprometimento do setor privado com a educação } \\
\text { e treinamento para o turismo }\end{array}$ & 4,53 & 1,515 & 5,18 & 1,388 \\
\hline Q61 & $\begin{array}{l}\text { Qualidades de empreendedorismo nos negócios } \\
\text { turísticos locais }\end{array}$ & 4,49 & 1,218 & 5,04 & 1,385 \\
\hline Q62 & Apoio da comunidade em eventos especiais & 4,95 & 1,073 & 5,64 & 1,177 \\
\hline Q63 & $\begin{array}{l}\text { Reputação do órgão da cidade responsável por atrair } \\
\text { visitantes }\end{array}$ & 4,60 & 1,767 & 4,61 & 1,556 \\
\hline
\end{tabular}

Fonte: Os Autores (2013)

Ao julgar individualmente os resultados dos indicadores de cada cidade, observou-se que as médias mais altas em Santana do Livramento, bem como os menores desvios-padrão, para os indicadores voltados à responsabilidade da atividade turística, são com os visitantes ou com a comunidade local. A cidade de Uruguaiana percebeu positivamente esta variável apenas na responsabilidade das empresas turísticas com as necessidades dos visitantes, entretanto, considerou e pontuou de forma elevada a qualificação dos empregados que atuam na área turística e o apoio da comunidade em eventos especiais.

VIEIRA, E. V.; HOFFMANN, V.E. Avaliação De Competitividade E Gerenciamento De Destinos Turísticos: Uma Aplicação No Sul Do Brasil. Revista de Empreendedorismo e 
Nessa linha, constatou-se a diferença existente nas duas cidades. Os santanenses parecem não chegar ao mesmo consenso quanto ao perfil qualificativo dos empregados da área turística, classificando-os, na sua maioria, abaixo do ponto central (4).

Assim sendo, e conforme aplicação no grupo anterior, procedeu-se a análise fatorial de componentes principais para a extração do número de fatores dos 11 indicadores desse grupo, onde foram relacionados 3 fatores. No processo de verificação da relação de cada indicador com os 3 fatores encontrados, observou-se que 2 indicadores não se relacionavam com nenhum dos 3 fatores localizados: Q56 (abrangência e qualidade dos programas de treinamento para a área turística) e Q63 (reputação do órgão da cidade responsável por atrair visitantes).

Tabela 5 - Componentes principais do gerenciamento da destinação - parte 2

\begin{tabular}{l|c|c|c|c}
\hline \multicolumn{2}{c|}{ Extração: componentes principais - Grupo 4 - gerenciamento da destinação - parte 2 } \\
\hline & $\begin{array}{c}\text { Valor da } \\
\text { variável/indicador }\end{array}$ & $\begin{array}{c}\text { \% total da } \\
\text { variância }\end{array}$ & $\begin{array}{c}\text { Cumulativo da } \\
\text { variável/indicador }\end{array}$ & $\begin{array}{c}\text { Cumulativo \% } \\
\text { da variância }\end{array}$ \\
\hline Fator 1 & 3,982253 & 36,20230 & 3,982253 & 36,20230 \\
\hline Fator 2 & 2,026550 & 18,42318 & 6,008803 & 54,62548 \\
\hline Fator 3 & 1,054459 & 9,58599 & 7,063261 & 64,21147 \\
\hline
\end{tabular}

Fonte: Os Autores (2013)

A análise discriminante (Tabela 6) permitiu inferir que todos os 3 fatores apresentaram-se significativos e, ao examinar cada indicador separadamente na função discriminante, observou-se que apenas 3 desses grupos apresentavam um $p$ $<0,05$. O maior poder discriminatório foi atribuído ao indicador da Q57 (perfil dos empregados na área turística - qualificação), com $p=0,000037$, seguido da Q62 (apoio da comunidade em eventos especiais), com $p=0,029083$, e da Q54 (responsabilidade do desenvolvimento da atividade turística com as necessidades da comunidade), com $p=0,039479$. É necessário dizer que cada um desses indicadores posiciona-se junto a um fator diferente.

VIEIRA, E. V.; HOFFMANN, V.E. Avaliação De Competitividade E Gerenciamento De Destinos Turísticos: Uma Aplicação No Sul Do Brasil. Revista de Empreendedorismo e 
Tabela 6 - Sumário da análise da função discriminante do gerenciamento da destinação - parte 2

\begin{tabular}{lccc}
\hline & Wilks' Lambda & F-remove & $p$-level \\
\hline FATOR 1 & 0,863005 & 14,85034 & 0,000160 \\
FATOR 2 & 0,868391 & 16,11622 & 0,000086 \\
FATOR 3 & 0,868256 & 16,08456 & 0,000087 \\
\hline
\end{tabular}

Fonte: Os Autores (2013)

Os indicadores que confirmaram significância, comprovando a desigualdade entre as médias encontradas nas cidades, parecem refletir a inexistência da consonância nas percepções das duas cidades acerca das afirmações de Go e Govers (2000) e Buhalis (2000), para os quais os esforços devem ser feitos por meio dos stakeholders turísticos para a entrega de produtos e serviços com qualidade aos visitantes, podendo gerar o aumento de competitividade a partir do momento que são oferecidos de modo confiável, como o uso da padronização, por exemplo (DWYER; KIM, 2001, 2003).

Não obstante pode-se perceber a distinção existente entre poder público e privado. Conforme elucidam Nascimento, Silva e Enders (2004), em uma pesquisa feita com empreendimentos turísticos e o setor público, foi possível reforçar essa distinção, pois o poder público acredita pertencer a uma posição maior de comando quanto às atitudes em relação ao turismo, preferencialmente sem a interferência da iniciativa privada, resultados semelhante ao que já havia sido encontrado por Costa e Hoffmann (2006). De todo modo, as médias encontradas neste indicador nas duas cidades são positivas, porém divergentes, pois os uruguaianenses perceberam de forma superior aos santanenses.

No que diz respeito especificamente aos indicadores responsabilidade do desenvolvimento da atividade turística com as necessidades da comunidade e perfil dos empregados na área turística (qualificação), sendo este último com $p$ inferior ao primeiro, evidenciando a diferença das médias e desvios-padrão das cidades, o resultado permitiu, novamente, remeter à questão do envolvimento da comunidade na participação da atividade turística (BUHALIS, 2000, YOON, 2002, HEATH, 2003, XAVIER, 2004, BERITELLI, 2011; COSTA, COSTA E MIRANDA JÚNIOR, 2012). 
Apesar da diferença nas médias encontradas no indicador responsabilidade do desenvolvimento da atividade turística com as necessidades da comunidade nas duas cidades, Santana do Livramento considerou-o mais positivamente que Uruguaiana, o que ratifica a ideia de que existem diferenças entre as cidades na questão dos recursos humanos, mais precisamente em relação aos residentes (comunidade), seja em um indicador ou em outro.

De forma mais contrastante, o indicador perfil dos empregados da área turística (qualificação) apresentou diferença significativa entre as cidades, onde Uruguaiana obteve médias mais altas que Santana do Livramento. Assim, Uruguaiana parece perceber este indicador de acordo com Udenal et al. (2004), que destaca o destino por meio da formação de mão de obra para a atividade turística, tanto através do governo local quanto da iniciativa privada, o que parece não ocorrer com os santanenses de forma tão favorável.

O que é possível inferir desse grupo é que as diferenças entre as cidades, apesar de existirem, foram menores em relação ao grupo na parte 1 , ou seja, as percepções sobre o gerenciamento de um destino nas duas cidades são menos distantes em relação a variáveis que contemplam as questões de capacitação e educação para a comunidade e para os visitantes.

O julgamento das formas de mensuração da competitividade de um destino dá-se por meio da avaliação de indicadores do macro ou micro ambiente (DWYER; $\mathrm{KIM}, 2001,2003)$. Nessa linha de análise, consideraram-se alguns indicadores do macro ambiente, tais como: número de empregos gerados, número de visitantes e turistas na cidade, o aparecimento de novos estabelecimentos turísticos, a satisfação da população com o turismo, a taxa de crescimento do turismo para a economia local, o valor dos salários pagos pelas organizações turísticas locais, a permanência do turista na cidade, o gasto efetuado pelo turista e visitante na cidade e a renda per capita da população.

Ao fazer uma análise comparativa das respostas observadas nas duas cidades com os dados percebidos pelos órgãos responsáveis do município, tais como Prefeitura Municipal e Secretarias Municipais (Quadro 1), Uruguaiana demonstrou similaridade entre o setor público e privado. Contudo, segundo a VIEIRA, E. V.; HOFFMANN, V.E. Avaliação De Competitividade E Gerenciamento De Destinos Turísticos: Uma Aplicação No Sul Do Brasil. Revista de Empreendedorismo e 
percepção do setor público, alguns desses indicadores do grupo não puderam ser obtidos com precisão em função da atividade de fronteira e suas interligações, tais como: a taxa de crescimento do turismo para a economia local e o gasto efetuado pelo turista e visitante na cidade. A explicação a ser buscada para inexatidão dos dados é corroborada por Sánchez (2002), cujos conceitos, que embasam a integração nas cidades de fronteiras e suas peculiaridades, alteram e mesclam os movimentos e a comunicação existente, perpassando os locais limítrofes. Nessa direção, torna-se impreciso inferir valores e percentuais exatos.

Pode-se inferir que Uruguaiana teve uma percepção semelhante diante da realidade percebida pelos governantes da cidade. Santana do Livramento não obteve resultados como Uruguaiana, mas em momento algum, a maioria dos respondentes notou esses indicadores como diminutos para o crescimento da atividade turística, mas sim como mantenedores, enquanto a percepção do setor público apontava, em alguns deles, para o crescimento.

O resultado apresentado indicou uma semelhança na classificação correta dos indivíduos das duas cidades, pois os percentuais estão próximos e foram superiores a $80 \%$. Os indicadores que fizeram a discrepância entre as duas cidades foram os mesmos com representatividade na comparação entre eles (indicadores) dentro de cada cidade separadamente. Ademais, estes indicadores foram os que apresentaram o maior índice de indivíduos bem classificados em relação aos grupos anteriores. 
Quadro 1: Comparativo entre os Stakeholders privado e público e o desempenho socioeconômico.

\begin{tabular}{|c|c|c|c|c|}
\hline \multirow{2}{*}{ Indicador } & \multicolumn{2}{|c|}{ Santana do Livramento } & \multicolumn{2}{|c|}{ Uruguaiana } \\
\hline & Privado & Público & Privado & Público \\
\hline O número de empregos gerados & $\begin{array}{l}\text { manteve } \\
(61)^{*}\end{array}$ & $\begin{array}{c}\text { aumento } \\
\mathrm{u}\end{array}$ & $\underset{(66)^{*}}{\operatorname{diminuiu}}$ & diminuiu \\
\hline $\begin{array}{l}\text { O número de turistas e visitantes na } \\
\text { cidade }\end{array}$ & $\begin{array}{l}\text { manteve } \\
(67)^{*}\end{array}$ & $\begin{array}{c}\text { aumento } \\
\mathrm{u}\end{array}$ & $\begin{array}{c}\text { diminuiu e } \\
\text { manteve } \\
(47)^{*}\end{array}$ & $\begin{array}{c}\text { aumento } \\
\mathrm{u}\end{array}$ \\
\hline $\begin{array}{l}\text { O aparecimento de novos } \\
\text { estabelecimentos turísticos }\end{array}$ & $\begin{array}{c}\text { manteve } \\
(81)^{*}\end{array}$ & manteve & $\begin{array}{c}\text { aumentou } \\
(72)^{*}\end{array}$ & $\begin{array}{c}\text { aumento } \\
\mathrm{u}\end{array}$ \\
\hline A satisfação da população com o turismo & $\begin{array}{c}\text { manteve } \\
(67)^{*}\end{array}$ & $\begin{array}{c}\text { aumento } \\
\mathrm{u}\end{array}$ & $\begin{array}{l}\text { manteve } \\
(58)^{*}\end{array}$ & manteve \\
\hline $\begin{array}{l}\text { Taxa de crescimento do turismo para a } \\
\text { economia local }\end{array}$ & $\begin{array}{l}\text { manteve } \\
(52)^{*}\end{array}$ & $\begin{array}{c}\text { aumento } \\
\mathrm{u}\end{array}$ & $\begin{array}{l}\text { manteve } \\
(58)^{*}\end{array}$ & $\begin{array}{c}\text { aumento } \\
\mathrm{u}\end{array}$ \\
\hline $\begin{array}{l}\text { O valor dos salários pagos pelas } \\
\text { organizações turísticas locais }\end{array}$ & $\begin{array}{c}\text { manteve } \\
(48)^{*}\end{array}$ & manteve & $\begin{array}{l}\text { manteve } \\
(54)^{*}\end{array}$ & manteve \\
\hline A permanência do turista na cidade & $\begin{array}{c}\text { manteve } \\
(60)^{*}\end{array}$ & $\begin{array}{c}\text { aumento } \\
\mathrm{u}\end{array}$ & $\begin{array}{l}\text { manteve } \\
(54)^{*}\end{array}$ & manteve \\
\hline $\begin{array}{l}\text { O gasto efetuado pelo turista e visitante } \\
\text { na cidade }\end{array}$ & $\begin{array}{l}\text { manteve } \\
(53)^{*}\end{array}$ & $\begin{array}{c}\text { aumento } \\
\mathrm{u}\end{array}$ & $\begin{array}{l}\text { manteve } \\
(52)^{*}\end{array}$ & $\begin{array}{c}\text { aumento } \\
\mathrm{u}\end{array}$ \\
\hline A renda per capita da população & $\begin{array}{c}\text { manteve } \\
(63)^{*}\end{array}$ & manteve & $\begin{array}{l}\text { diminuiu e } \\
\text { manteve } \\
(48)^{*}\end{array}$ & manteve \\
\hline
\end{tabular}

Número de respondentes.

Fonte: Os Autores (2013).

\section{Considerações Finais}

Os elementos essenciais ao turismo são determinados, em grande parte, pelas ações públicas e políticas governamentais. Nesse contexto, três aspectos são destacados como relevantes no modelo proposto por Dwyer e Kim (2001): a coordenação, como função primária desempenhada pela gestão do destino, que apoia a comunidade e múltiplas organizações presentes, tanto públicas quanto privadas; o abastecimento da informação, que quando disseminada a todos consiga produzir efetividade no posicionamento competitivo; e o monitoramento e a avaliação, que servem para guiar as políticas e a formulação das estratégias no sentido competitivo, além do julgamento sistemático das já existentes.

É sobremodo importante destacar que, a questão do posicionamento competitivo para ganho de mercado está associada à complexa ação e coordenação de todos os interessados (UYSAL et al., 2000). Isto justifica que não se infere perda 
de posicionamento de mercado apenas pela percepção de uma administração municipal mais negativa que positiva. Mesmo que as PMEs não percebam uma cooperação muito positiva entre o setor público e o privado, o setor público apresenta-se otimista em relação às PMEs estudadas no que tange à taxa de crescimento do turismo para a economia local.

Pelas considerações de Enright e Newton (2004), um destino só é competitivo se puder atrair e satisfazer o turista não só pelos fatores particulares do turismo (infraestrutura e atratividade), mas também pela gama de fatores que afetam a entrega desse produto, o que passa pela questão do planejamento e satisfação da comunidade, para a garantia da continuidade da atividade. De todo modo, é preciso considerar a questão "fronteira" entre dois países e a relação entre os laços, sejam eles afetivos ou de negócios (SÁNCHEZ, 2002), como é o caso dos dois municípios estudados que possuem nos países vizinhos um reconhecido e desenvolvido comércio voltado ao turismo de compras. A integração com cidades de outros países, observando-se a geografia de fronteira, denota particularidades que afetam o comportamento dos que nela vivem e, portanto, reflete em atitudes que podem ser diferenciadas conforme esse grau de relacionamento (SANCHÉZ, 2002).

O Modelo de Dwyer e Kim $(2001 ; 2003)$ permitiu, após análise de cada quadrante em particular, inferir que as cidades de Santana do Livramento e Uruguaiana, mesmo com semelhanças na sua cultura, porte, área de localização geográfica e tipo de atividade turística, valorizam positivamente alguns aspectos que uma e outra não percebem da mesma maneira. Uruguaiana destacou-se pelo desempenho socioeconômico (na comparação com o realizado pelo destino), e Santana do Livramento obteve resultados mais afirmativos nos recursos de apoio e gestão do destino de um modo geral.

$\mathrm{Na}$ tentativa de buscar respostas, parece que a cidade de Santana do Livramento acredita que o poder público pode fazer mais pela cidade e suas PMEs turísticas, já que existe cooperação entre as empresas da área, ou seja, reconhecem e executam seu papel dentro da cidade para o crescimento do turismo. Este cenário parece ser comum em cidades do interior onde acredita-se que as iniciativas para o desenvolvimento e crescimento local sejam advindas principalmente (ou somente) VIEIRA, E. V.; HOFFMANN, V.E. Avaliação De Competitividade E Gerenciamento De Destinos Turísticos: Uma Aplicação No Sul Do Brasil. Revista de Empreendedorismo e 
do poder público. Uruguaiana, por sua vez, parece acreditar mais no papel do poder público, dividindo as responsabilidades de crescimento e desenvolvimento com maior apoio das PMEs privadas.

Posta assim a questão, salienta-se que o presente estudo procurou contribuir para o entendimento de como se posiciona a competitividade nas cidades de Santana do Livramento e Uruguaiana e, dessa forma, cumpre mencionar que os resultados desta pesquisa não podem ser generalizados a todas as cidades do estado do Rio Grande do Sul, bem como de outras regiões do país. Isto em si enseja uma possível continuação deste estudo.

Como remate, sugere-se uma ampliação desta pesquisa nas cidades vizinhas de fronteira, como Rivera no Uruguai e Paso de los Libres na Argentina. Entretanto, há ainda a possibilidade de investigar outras cidades, tanto no estado do Rio Grande do Sul, como em outros estados brasileiros que possuam perfil de fronteira para futuras comparações.

\section{Referências}

BERITELLI, P. Cooperation among prominent actors in a tourist destination. Annals of Tourism Research, v. 38, n.2, 607-629, 2011 DOI: 10.1016/j.annals.2010.11.015

BARBETTA, P. A. Estatística aplicada às ciências sociais. 4aa ed. Florianópolis: Editora da UFSC, 2001.

BAPTISTA, M. Turismo: gestão estratégica. São Paulo: Verbo, 2003.

BARNEY, J. Firm resources and sustained competitive advantage. Journal of Management, v. 17, n. 1, p. 99-120, 1991.

BONET, L. La estrategia de turisme de Barcelona, un consorcio público-privado de éxito. In J. F. SENTIAS (Coords.), Casos de turismo cultural: de la planificación 
estratégica a la gestión del producto (Cap. 9, pp. 235-260). Barcelona: Ariel, 2004.

BORDAS, E. Competitiveness of tourist destinations in long distance markets. The Tourist Review, v. 47, n. 3, p. 3-9, 1994.

BUHALIS, D. Marketing the competitive destination in the future. Tourism Management, v. 21, n. 1, p. 97-116, 2000.

CAPONE, F. Regional competitivness in tourist local systems. EUROPEAN REGIONAL SCIENCE ASSOCIATION, 2004, Porto. Proceedings ... Portugal, Porto: ERSA, 2004.

$\mathrm{CHO}, \mathrm{V}$. Tourism forecasting and its relationship with leading economic indicators. Journal of Hospitality and Tourism Research, v. 25, n. 4, p. 399-420, 2001.

COOPER, C.; FLETCHER, J.; WANHILL, S.; GILBERT, D. SHEPHERD, R. Turismo: princípios e prática. 2. ed. São Paulo: Bookman, 2002.

COSTA, H. A. Análise das relações de rede e do perfil da competitividade turística: estudo comparativo entre São Francisco do Sul e Laguna - SC. Dissertação (Mestrado em Turismo e Hotelaria). Universidade do Vale do Itajaí, 2005.

COSTA, H. A.; COSTA, A. C.; MIRANDA JÚNIOR, N. S. Arranjos Produtivos Locais (APL) no Turismo: estudo sobre a competitividade e o desenvolvimento local na Costa dos Corais - AL. Revista Acadêmica do Observatório de Inovação do Turismo, v. 7, n. 1, p. 1-31, 2012.

COSTA, H. A.; HOFFMANN, V.E. Competitividade de destinações turísticas: elementos e indicadores aplicados no estudo da administração turística de Balneário Camboriú - SC, Brasil. Turismo em Análise, v. 17, n.2, p. 135-154, 2006.

VIEIRA, E. V.; HOFFMANN, V.E. Avaliação De Competitividade E Gerenciamento De Destinos Turísticos: Uma Aplicação No Sul Do Brasil. Revista de Empreendedorismo e 
COYNE, K. P. Sustainable competitive advantage - What It Is, What It Isn't. Business Horizons, p.54-61, Jan./ Feb. 1986.

$\mathrm{CROUCH}, \mathrm{G}$. Effect of income and price on international tourism demand. Annals of tourism research, v. 19, n. 4, p. 643-664, 1992.

CROUCH, G. I.; RITCHIE, J. R. B. Tourism, competitiveness and societal prosperity. Journal of Business Research, v. 44, n. 3, p. 137-152, 1999.

DINIZ FILHO, L. L.; VICENTINI, Y. Teorias espaciais contemporâneas: o conceito de competitividade sistêmica e o paradigma da sustentabilidade ambiental. Desenvolvimento e Meio Ambiente, n. 9, p. 107-116, 2004.

DWYER, L.; KIM, C. Destination competitiveness: development a model with application to Australia and Republic of Korea. Report prepared for Department of Industry Science and Resources, Australia and Korea Tourism Research Institute. Ministry of Tourism, October, 2001.

Destination competitiveness: determinants and indicators. Current Issues in Tourism, v. 6, n. 5, p. 369-414, 2003.

DWYER, L., N. MISTILIS, P. FORSYTH, AND P. RAO. 2001. International Price Competitiveness of Australia's MICE Industry. International Journal of Tourism Research, v. 3, n. 2, p. 123-40, 2001.

ENRIGHT, M. J.; NEWTON, J. Tourism destination competitiveness: a quantitative approach. Tourism management, v. 25, n. 6, p. 777-788, 2004.

ESSER, K.; HILLEBRAND, W.; MESSNER, D.; MEYER-STAMER, J. Competitividad sistémica: competitividad internacional de las empresas y políticas VIEIRA, E. V.; HOFFMANN, V.E. Avaliação De Competitividade E Gerenciamento De Destinos Turísticos: Uma Aplicação No Sul Do Brasil. Revista de Empreendedorismo e 
requeridas. Instituto Alemán de Desarrollo, Berlin, 1994. Disponível em: <http://www.meyer-stamer.de/1994/systemsp.htm>. Acesso em 10 maio 2006.

FONSECA, A. A.; FONSECA, P. A. Contribuição das estratégias de desenvolvimento turístico para o papel social das organizações. In: BAHL, M. (Org.) Turismo com responsabilidade social. São Paulo: Roca, 2004.

GO, F. M.; GOVERS, R. Integrated quality management for tourist destinations: a European perspective on achieving competitiveness. Tourism Management, v. 21, n. 1 , p. $79-88,2000$.

HAIR, J. F.; ANDERSON, R. E.; TATHAM, R. L.; BLACK, W. C. Análise multivariada de dados. $5^{\mathrm{a}}$ ed. Porto Alegre: Bookman, 2005.

HASSAN, S. Determinants of market competitiveness in an environmentally sustainable tourism industry. Journal of Travel Research, v. 38, n. 3, p. 239-245, 2000.

HEATH, E. Towards a model to enhance destination competitiveness: a South Africa perspective. Journal of Hospitality \& Tourism Management, v. 10, n. 2, p. 124141, 2003.

HENRIQUES, H. L.; LIMA, I. S. M. Responsabilidade social do turismo na inclusão da pessoa portadora de deficiência ou com mobilidade reduzida. In: BAHL, M. (Org.) Turismo com responsabilidade social. São Paulo: Roca, 2004.

HOFFMANN, V. E.; CAMPOS, L. M. S. Instituições de suporte, serviços e desempenho: um estudo em aglomeração turística de Santa Catarina. Revista de Administração Contemporânea, v. 17, n. 1, p. 18-41, 2013. 
IBGE. Estudos e Pesquisas. Informação Econômica, n 5 . Economia do Turismo. Análise das Atividades características do turismo, 2003. Rio de Janeiro, 2007.

JAMIESON, W. Defining urban tourism destination management. In: (Org.) Community tourism destination management: principles and practices. Pathumthani: Saengsawang World Press, 2001.

JONKER, J. A. The strategic identification and integration of critical success factors to archieve international competitiveness for South África as a tourism destination. 2004. 412 f. Thesis - Faculty of Economic and Management Sciences, University of Pretoria, Pretoria, 2004.

JONKER, J. A.; HEATH, E. T.; DU TOIT, C. M. The identification of managementprocess critical success factors that will achieve competitiveness and sustainable growth for South Africa as a tourism destination. Southern African Business Review, v. 8, n. 2, p. 1-15, 2004.

KOTLER, P.; GERTNER, D.; REIN, I.; HAIDER, D. Marketing de lugares: como conquistar crescimento de longo prazo na América Latina e no Caribe. São Paulo: Prentice Hall, 2005.

KOZAK, M.; RIMMINGTON, M. Measuring tourist destination competitiveness: conceptual considerations and empirical findings. International Journal of Hospitality Management, v. 18, n. 3, p. 273-283, 1999.

MAZARO, R. M.; VARZIN, G. Modelos de competitividad para destinos turísticos en el marco de la sostenibilidad. Revista de Administração Contemporânea, v. 12, n. 3, art. 8, p. 789-809, 2008.

MILMAN, A.; PIZAM, A. The role or awareness and familiarity with a destination. Journal of Travel Research, v. 33, n. 3, p. 21-31,1995.

VIEIRA, E. V.; HOFFMANN, V.E. Avaliação De Competitividade E Gerenciamento De Destinos Turísticos: Uma Aplicação No Sul Do Brasil. Revista de Empreendedorismo e 
MOTTIAR, Z.; TUCKER, H. Webs of power: multiple ownership in tourism destinations. Current Issues in Tourism, v. 10, n. 4, 2007.

NASCIMENTO, F. M.; SILVA, L. M. T.; ENDERS, W. T. Criação de parcerias entre poder público e setor hoteleiro para dinamizar o legado cultural regional. In: BAHL, M. (Org.) Turismo com responsabilidade social. São Paulo: Roca, 2004.

NEELY, A.; GREGORY, M.; PLATTS, K. Performance measurement system design: a literature review and research agenda. International Journal of Operations and Production Management, v. 15, n. 4, p. 85-116, 1995.

NEWALL, J.E. The challenge of competitiveness. Business Quarterly, v. 56, n. 4, p. 94-100, 1992.

PAGE, S. J. Tourism management: managing for change. Oxford: Elsevier, 2005.

PÉREZ, A. S.; MESANAT, G. G. Que indica un indicador? Análisis comparative en los destinos turísticos. In: SIMPOSIO INTERNACIONAL DE TURISMO Y OCIO, 14., 2006, Barcelona. Anais... Barcelona: ESADE, 2006.

PHILLIPS, P. A. Perceptual measurement systems and hotels: a conceptual framework. International Journal of Hospitality Management, v. 18, n. 2, p. 171182, 1999.

PORTER, M. E. Estratégia competitiva: técnicas para análise de indústrias e da concorrência. $7^{\mathfrak{a}}$ ed. Rio de Janeiro: Campus, 1986.

. A vantagem competitiva das nações. Rio de Janeiro: Campus, 1993.

VIEIRA, E. V.; HOFFMANN, V.E. Avaliação De Competitividade E Gerenciamento De Destinos Turísticos: Uma Aplicação No Sul Do Brasil. Revista de Empreendedorismo e 
RITCHIE, J. R. B.; CROUCH, G. I. The competitive destination: a sustainability perspective. Tourism Management, v. 21, n. 1, p. 1-7, 2000.

SÁNCHEZ, A. Q. A fronteira inevitável: um estudo sobre as cidades de fronteira de Rivera (Uruguai) e Santana do Livramento (Brasil) a partir de uma perspectiva antropológica. 2002. 209 f. Tese (Doutorado em Antropologia Social). Programa de Pós-Graduação em Antropologia Social.Universidade Federal do Rio Grande do Sul, Porto Alegre, 2002.

SEBRAE. A Competitividade nos Setores de Comercio, de Serviços e de Turismo no Brasil: Perspectivas até 2015: Tendências e Diagnósticos / Confederação Nacional do Comércio de Bens, Serviços e Turismo (CNC); Serviço Brasileiro de Apoio às Micro e Pequenas Empresas (Sebrae). Brasília: CNC; Sebrae, 2008.

SELIN, S.; BEASON, K. Interorganizational relations in tourism. Annals of Tourism Research, v. 18, n. 4, p. 639-652, 1991.

UDENAL, A. P. Z.; CAMPOS, C. F.; FAXINA, F. Turismo e empregabilidade no meio rural. In: BAHL, M. (Org.) Turismo com responsabilidade social. São Paulo: Roca, 2004.

UYSAL, M.; CHEN, J. S.; WILLIAMS, D. R. Increasing state market share through a regional position. Tourism Management, v. 21, n. 1, p. 89-96, 2000.

XAVIER, H. Incorporação da dimensão social na formação profissional do turismo. In: BAHL, M. (Org.) Turismo com responsabilidade social. São Paulo: Roca, 2004. 
YILMAZ, Y.; BITICI, U. S. Performance measurement in tourism: a value chain model. International Journal of Contemporary Hospitality Management, v. 18, n. 4, p. 341-349, 2006.

YOON, Y. Development of a structural model for tourism destination competitiveness from stakeholders' perspectives. 2002. $228 \mathrm{f}$. Thesis - Faculty of the Virginia Polytechnic Institute, University of Virginia, Blacksburg, 2002.

ZERMIANI, B. B.; CRUZ, M. B.; WÖHLKE, M. Turismo e portadores de necessidades especiais: relatos de experiência "colônia de férias especiais tempo feliz" - Balneário Camboriú/SC. In: BAHL, M. (Org.) Turismo com responsabilidade social. São Paulo: Roca, 2004.

Artigo recebido em 11/03/2013. Aprovado em 30/04/2013. 